\title{
The Impact of Hydrogen Peroxide as An Oxidant for Solvent-free Liquid Phase Oxidation of Benzyl Alcohol using Au-Pd Supported Carbon and Titanium Catalysts
}

\author{
Sarhan Sanaa Tareq1,2,*, Mohd. Izham Saiman', Taufiq-Yap Yun Hin', \\ Abdul Halim Abdullah ${ }^{1}$, Umer Rashid ${ }^{3}$
}

${ }^{1}$ Catalysis Science and Technology Research Centre, Faculty of Science, Universiti Putra Malaysia, 43400 Serdang, Selangor, Malaysia

${ }^{2}$ Department of Chemistry, Faculty of Science for Women, University of Baghdad, Baghdad, Iraq

${ }^{3}$ Institute of Advanced Technology, Universiti Putra Malaysia, 43400 Serdang, Selangor, Malaysia

Received: $8^{\text {th }}$ May 2017; Revised: $22^{\text {nd }}$ February 2018; Accepted: $6^{\text {th }}$ March 2018; Available online: $11^{\text {st }}$ June 2018; Published regularly: $1^{\text {st }}$ August 2018

\begin{abstract}
The solvent free oxidation of benzyl alcohol was conducted employing $\mathrm{Au}$ and $\mathrm{Pd}$ supported catalysts, while utilizing hydrogen peroxide $35 \%\left(\mathrm{H}_{2} \mathrm{O}_{2}\right)$ as the oxidant, $\mathrm{H}_{2} \mathrm{O}_{2}$ is very cheap, mild, and an environment friendly reagent, which produced water as the only by-product. Various proportions of Au-Pd catalysts on carbon and titanium oxide activated as supports were synthesized through the use of sol immobilization catalyst synthesis technique. Characterization of the synthesized catalysts was performed using X-Ray Diffraction (XRD), Brunauer-Emmett-Teller (BET), Field Emission Scanning Electron Microscopy (FESEM), and Transmission Electron Microscopy (TEM). It was found that the synthesized $\mathrm{Au}-\mathrm{Pd} /$ activated carbon catalyst was beneficial for the solvent free oxidation of benzyl alcohol after its containing high surface area measuring $871 \mathrm{~m}^{2} \mathrm{~g}^{-1}$. Analysis of the TEM data and particle dimension revealed smaller and narrower particle size of $1 \mathrm{wt} \%$. Thus, the distribution of $\mathrm{Au}-\mathrm{Pd} / \mathrm{C}$ was attained. Carbon-supported bimetallic catalysts presented a higher conversion compared to catalysts that are supported titanium oxide $\left(\mathrm{TiO}_{2}\right)$ for for the oxidation reaction of benzyl alcohol. It was determined that this technique was a suitable process for catalyst synthesis with high selectivity, same distribution of the particle size and activations. Copyright (C) 2018 BCREC Group. All rights reserved
\end{abstract}

Keywords: Benzyl Alcohol; Solvent Free Oxidation; Hydrogen Peroxide; Palladium and Gold Supported Catalyst

How to Cite: Sanaa Tareq, S., Saiman, M.I., Yun Hin, T.Y., Abdullah, A.H., Rashid, U. (2018). The Impact of Hydrogen Peroxide as An Oxidant for Solvent-free Liquid Phase Oxidation of Benzyl Alcohol using Au-Pd Supported Carbon and Titanium Catalysts. Bulletin of Chemical Reaction Engineering \& Catalysis, 13 (2): 373-385 (doi:10.9767/bcrec.13.2.1204.373-385)

Permalink/DOI: https://doi.org/10.9767/bcrec.13.2.1204.373-385

\section{Introduction}

Using primary alcohol for the selective oxidation within aqueous stage by using molecular

* Corresponding Author.

E-mail: mohdizham@upm.edu.my (M.I. Saiman)

Tel: +603-89467238(DL)/6775(GL) Faks: +603-89435380 oxygen or hydrogen peroxide as alternatives to their retained ketones or aldehydes is currently viewed as the most industrially viable and sustainable method for producing fine chemicals [15]. Traditionally, oxidation reactions of this nature are conducted with the use of varying quantities of oxygen contributors, such as: po- 
tassium permanganate or chromium oxide. However, given their high cost and toxic environmental effects, these reagents are no longer considered sustainable for producing fine chemicals [6-8].

Several studies were conducted to study the possibility of using gold catalyst to produce fine chemicals within the liquid phase. The studies subsequently provided a definition for their utilisation in a specific cationic gold, and it was for the first time discovered as an active heterogeneous catalyst [1]. Metallic gold was previously regarded to be an inactive catalyst for synthesising fine chemicals [9]. However, a noteworthy catalytic behaviour of gold has recently discovered. This discovery displays that the catalytic activity of gold is related to the formation of the small particles due to the lack of ability of the larger particles to perform chemical absorption for the unique reactant molecules to any extent [10,11]. It is known that the Au-based catalyst is highly effective in alcohol oxidation [12]. Furthermore, gold catalyst was determined to be an active oxidant for alcohols containing $\mathrm{O}_{2}$ [13]. Among the broad range of metals that were previously examined as alloys, palladium and gold were considered as the most interesting alloys due to their unique catalytic characteristics [14].

Various studies have recently made use of the bimetallic gold-palladium catalysts to serve as accelerators for producing fine chemicals reactions, such as the oxidation of alcohols to produce their respective aldehydes or ketones $[15,16]$, synthesising of $\mathrm{H}_{2} \mathrm{O}_{2}$ [17], the synthesis of vinyl acetate $\left(\mathrm{C}_{4} \mathrm{H}_{6} \mathrm{O}_{2}\right)$ [18], and the hydrogenation reaction of unsaturated compounds, among others. Current studies have demonstrated that utilising a secondary metal component such as $\mathrm{Pd}$ to enhance the Au catalyst's lifetime could be helpful in terms of selectivity and activity for various reactions [7,19]. Thus, the addition of $\mathrm{Pd}$ to $\mathrm{Au}$ catalysts produces durable catalysts that are capable of remaining very active during the process of direct synthesis [20]. This paper focused on the use of active $\mathrm{Au}-\mathrm{Pd}$ catalysts once supported by $\mathrm{TiO}_{2}$ and once more by carbon for the purpose of benzyl alcohol oxidation with the advantage of oxidation reaction without adding solvents. Also, we used $\mathrm{H}_{2} \mathrm{O}_{2}$ as an environment friendly oxidant for benzyl alcohol oxidation reaction in comparison to using permanganate and dichromate, as well as conducting a detailed characterization study of the used materials in the experimental aspect of this research. The catalyst, which was synthesized, was tested for its efficacy, which was found positive in the reaction media.

\section{Materials and Methods}

\subsection{Materials}

Activated carbon (Draco-G60) $\mathrm{PdCl}_{2}, \mathrm{TiO}_{2}$ (Degussa, P25), $\mathrm{HAuCl}_{4} .3 \mathrm{H}_{2} \mathrm{O}, \mathrm{NaBH}_{4}(>96 \%$ ), and polyvinyl alcohol (PVA) (molecular weight $\mathrm{Mw}=9,000-10,000 \mathrm{~g} / \mathrm{mol} 80 \%$ hydrolyzed) were procured from Aldrich.

\subsection{Sol immobilization method}

The sol immobilization technique was utilized to synthesis a range of catalysts formed by mono $\mathrm{Au}$ or $\mathrm{Pd}$, and bimetallic catalysts based on Au-Pd [21,22], over supported $\mathrm{TiO}_{2}$ and activated carbon (Draco-ag60, Aldrich). Aqueous solutions of $\mathrm{PdCl}_{2}$ and $\mathrm{HAuCl}_{4} .3 \mathrm{H}_{2} \mathrm{O}$ having the desired concentrations were prepared. Polyvinal alcohol (PVA) having (1\% weight solution) was then supplied to the solution previously prepared. A newly prepared $0.1 \mathrm{M}$ $\mathrm{NaBH}_{4}$ solution then was mixed to synthesize a dark brown sol. Thirty minutes later, generation of the sol immobilisation of the colloid was done through addition of the support material (titania and carbon) and the sulphuric acid together under intensive stirring to achieve a $\mathrm{pH}$ of (1-3). Computation of the required stoichiometric quantity of the support material was done. Then, the whole metal oxide loading having $1 \mathrm{wt} \%$ was generated. The catalyst slurry produced from this process was filtered before being thoroughly washed with $2 \mathrm{~L}$ of distilled water. Then, it was oven dried at $120^{\circ} \mathrm{C}$ for $16 \mathrm{~h}$. For the monometallic catalyst, the required metal loading (1\% wt total metal) was adjusted as needed by altering the aqueous metal precursor's volume. The mentioned procedure above was then done again the same way.

\subsection{Catalytic activity for oxidation reac- tion}

The reactions took place in a glass reactor of (30 $\mathrm{mL})$ that had been supplied by a reflux condenser. The reactor was excited in an oil bath and simultaneously subjected to intensive stirring. In a traditional preparation method, hydrocarbon (e.g. $10 \mathrm{~mL}$ benzyl alcohol) is mixed with the required amount of catalyst in a round bottom flask. $\mathrm{H}_{2} \mathrm{O}_{2}$ was then added as the oxidant. The resulting mixture underwent vigorous stirring and heating at the desired temperature for 4 hours and in an atmosphere. 
After the reaction was completed, a centrifuge was used to remove the catalyst from the reaction mixture. The products were identified and analysed using gas chromatograph flame ionisation detector (GC-FID) and gas chromatograph mass spectrometer (GC-MS). After the reaction was completed, $500 \mu \mathrm{L}$ of acetone was added as an internal standard to the reaction products. The reaction products did not react with the internal standard, which is eluted from the column for regular periods of time. Then collected $0.5 \mu \mathrm{L}$ of the reaction mixtures by direct injections to be analyzed using Gas Chromatography (GC).

Using the internal calibration curve and the acetone as an internal standard, the catalytic data for reactions were calculated. Also the carbon balance of the reaction was determined by the means of the Internal standard. For purpose of calculating the calibration factors (CF) for both standards, we used Equation (1), where the concentration and mole (mole \%), were determined according the GC analysis results in the area of substrate and products. To obtain the calibration curve for benzyl alcohol, the concentrations of benzyl alcohol have been used, where the calibration factor calculated as it is shown in Equations (1) and (2).

$C F=\frac{\text { mole }(\text { benzylalchohol })}{\text { mole }(\text { acetone })} \times \frac{\text { Area }(\text { acetone })}{\text { Area }(\text { benzylalcohol })}$

$$
\begin{aligned}
\text { Mole of Compound }= & \text { mole }(\text { acetone }) \times C F \\
& x \frac{\text { Area }(\text { benzyl alcohol })}{\text { Area }(\text { acetone })}
\end{aligned}
$$

The quantity of consuming reactants and the generating products were calculated using Equations (3) and (4) as conversion and selectivity.

$$
\text { Conversion }(\%)=\frac{\text { mole of benzyl alchohol reacted }}{\text { total mole of benzyl alcohol }} \times 100 \%
$$

Selectivit $y(\%)=\frac{\text { mole of product formed }}{\text { mole of benzyl alcohol reacted }} \times 100 \%$

\subsection{Catalyst characterization}

A UV spectrometer (UV-1650 PC SHIMADZU B) was used to carry out the ultraviolet visible spectra of the synthesised sols in $\mathrm{H}_{2} \mathrm{O}$ within the 200-900 $\mathrm{nm}$ range in a quartz cu- vette. A Kratos Axis ultra DLD spectrometer was used to record the X-ray photoelectron spectra with the help of monochromatized Xray source for $\mathrm{Al}$ and $\mathrm{K}_{\mathrm{a}}$. It utilised the analyser pass energies of $40 \mathrm{eV}$ for detail scans and $160 \mathrm{eV}$ survey scans.

The transmission electron microscopy (TEM) analysis was utilized to determine particle size and was conducted with the use of a (Hitachi H-7100, Japan) microscope operating at $80-200 \mathrm{kV}$. Samples of the catalyst powder were distributed in ethanol through an ultrasonic bath that operated for 15 minutes. Field emission scanning electron (FE-SEM) (JEOLFE-SEM model JSM 7600F) was used to determine the morphology of the catalyst samples at a quite high degree of magnification and utilizing the field emission current. The BrunaureEmmett-Teller (BET) surface area analysis method (Micromeritics ASAP2010) was later utilized to conclude the overall surface area of the catalyst. The analysis was conducted with the multi-point nitrogen gas adsorptiondesorption isotherm $\left(-196{ }^{\circ} \mathrm{C}\right)$ given a pressure variety of $0.07<\mathrm{P} / \mathrm{P}_{0}<0.3$. The Shimadzu diffractometer (model XRD 6000) was used to analyse the X-ray diffraction (XRD) through the use of $\mathrm{Cu}-\mathrm{Ka}$ radiation ( $\mathrm{kW}$ and $30 \mathrm{~mA}$ ) and given a wavelength $(\lambda)$ of $1.54 \mathrm{~A}$. This was conducted over the $2 \theta$ range for $10^{\circ}$ to $80^{\circ}$ given a $0.04^{\circ}$ step every time and a screening speed equal to $2 \mathrm{~min} /$ degree. The DebyeScherrer's equation was then used to calculate the crystallite sizes of the catalyst samples.

\section{Results and Discussions}

\subsection{UV-vis spectra of colloidal sols}

Characterisation of the colloidal sols (prior to immobilisation on a support) was performed using the UV spectrometer in $\mathrm{H}_{2} \mathrm{O}$ given the range of 200 and $900 \mathrm{~nm}$. The location and strength of the Plasmon resonance band of the metal nanaoparticles were determined using a quartz cuvette. For the pure $\mathrm{Au}$ sol band, the resonance band was set at $450 \mathrm{~nm}$, while the resonance band of the $\mathrm{Au}$ and $\mathrm{Pd}$ mixture was set at $350 \mathrm{~nm}$ and $500 \mathrm{~nm}$, as shown in Figure 1. The Au sol's ultraviolet-visible spectrum was recorded and it demonstrated a total reduction in terms of the Au(III) species [21]. The presence of the Plasmon resonance that was seen at $500 \mathrm{~nm}$ is considered a characteristics of the gold nanoparticles that have particle dimensions that are smaller than $10 \mathrm{~nm}[19,23]$.

The disappearance of the gold surface band was observed by studying the spectra that was produced by the mixture of the sols of 
the two metal Au-Pd nanoparticles. Furthermore, the study confirmed the UV-visible spectrum of Au-Pd sol, which demonstrated a decrease in the absolute $\left(\mathrm{AuCl}^{-4}\right)$. The $\mathrm{UV}$-vis spectr for the mono and bimetallic sol agree with the data that was published previously by $[19,23]$.

\subsection{Transmission electric microscopy analysis (TEM)}

Figure 2 presents the TEM images for the dried $1 \mathrm{wt} \% \mathrm{Au}-\mathrm{Pd} / \mathrm{TiO}_{2}$, and $1 \mathrm{wt} \% \mathrm{Au}-\mathrm{Pd} / \mathrm{C}$ samples after calcination in open air at $250{ }^{\circ} \mathrm{C}$ for $3 \mathrm{~h}$. Assessment of the distribution of the particle dimensions of the organized catalyst samples were conducted utilizing the TEM characterisation method. The histograms derived from the particle dimension dispersal are presented in Figure 3. The image-J software was used to measure the particle size distributions, which were computed based on the particle dimension analysis and TEM data. It was able to achieve smaller and narrower particle dimensions for the $1 \mathrm{wt} \% \mathrm{Au}-\mathrm{Pd} / \mathrm{C}$ distribution. This agrees with the results presented by Dimitratos and co-workers [24,25]. Also, for carbon supported Au-pd colloid, the mean particle sizes were $5.5 \pm 0.9$, while the mean particle sizes were $14.2 \pm 0.9 \mathrm{~nm}$ for Au-Pd supported titanium. Compared to that of carbon, the

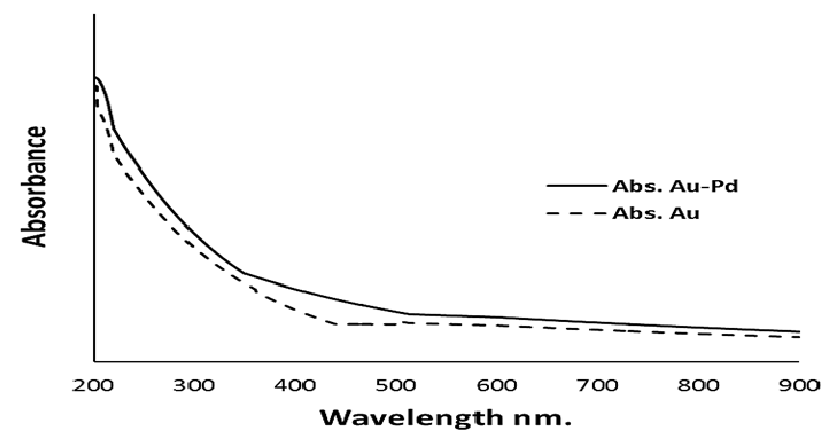

Figure 1. UV-vis spectra of $\mathrm{Au}$ and $\mathrm{Au}-\mathrm{Pd}$ sol study observed a minor rise in particle dimension after colloid was immobilized on $\mathrm{TiO}_{2}$.

\subsection{FESEM and EDX analysis of the catalyst samples}

EDX and FESEM were conducted on the samples of the synthesized catalyst so that the composition and the surface morphology of the elements in the catalysts can be studied, respectively. Figure 4 (a) and (b) showed the electron micrographs of $\mathrm{Au}-\mathrm{Pd} / \mathrm{TiO}_{2}$ and $\mathrm{Au}-\mathrm{Pd} / \mathrm{C}$ catalysts, respectively. The micrograph illus-
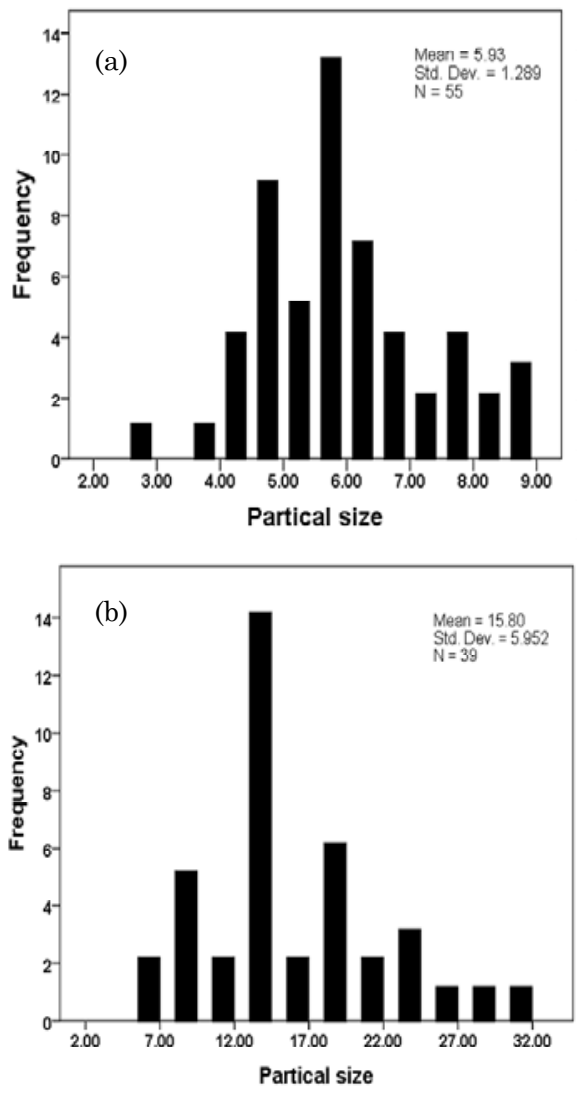

Figure 3. Particle size distributions for (a) 1 wt $\%(\mathrm{Au}-\mathrm{Pd}) / \mathrm{C}$, and (b) $1 \mathrm{wt} \%(\mathrm{Au}-\mathrm{Pd}) / \mathrm{TiO}_{2}$ synthesised using the sol-immobilisation method
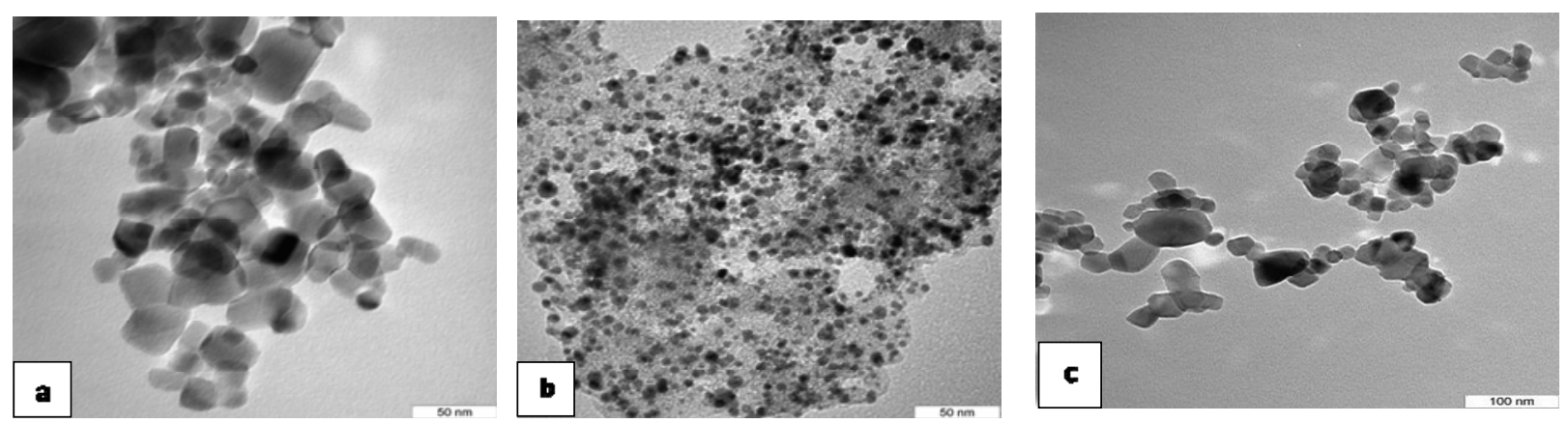

Figure 2. TEM images of (a) $1 \mathrm{wt} \%$ (Au-Pd)/TiO 2 , (b) $1 \mathrm{wt} \%$ (Au-Pd)/C, (c) $1 \mathrm{wt} \%(\mathrm{Au}-\mathrm{Pd}) / \mathrm{TiO}_{2}$ after calcination at $250^{\circ} \mathrm{C}$ for $3 \mathrm{~h}$ in the open air 
trated that both catalyst samples, the nanoparticles were well dispersed on the surfaces of the titanium oxide and activated carbon. The two images also revealed that the catalyst particles were distributed homogenously as a result of the small size of the particles of the Au-Pd. A small disparity was observed in the distribution of the particle size between samples of Au$\mathrm{Pd} / \mathrm{TiO}_{2}$ and $\mathrm{Au}-\mathrm{Pd} / \mathrm{C}$. Au-Pd/C exhibited a better and more homogeneous particle size distribution, which is believed to be a result of the smaller particle size of the carbon support. Figure 4 presents the EDX spectra that supports the existence of $\mathrm{Au}-\mathrm{Pd} / \mathrm{TiO}_{2}$ and $\mathrm{Au}-\mathrm{Pd} / \mathrm{C}$.

\subsection{Brunauer-Emmet-Teller (BET) surface area analysis}

Table 1 presents the textural characteristics of the catalysts that have supports. The samples of the catalyst were degassed at $150{ }^{\circ} \mathrm{C}$ for $10 \mathrm{~h}$ so that contaminants, like $\mathrm{CO}_{2}$ and water are eliminated before analysis. It was establish that the $1 \mathrm{wt} \%(\mathrm{Au}-\mathrm{Pd}) / \mathrm{C}$ catalyst had a pore volume of $0.8107 \mathrm{~cm}^{2} \mathrm{~g}^{-1}$, a pore radius of 1.86 $\mathrm{nm}$, and a total surface area of $870.06 \mathrm{~m}^{2} \mathrm{~g}^{-1}$. On the other hand, samples of $1 \mathrm{wt} \% \mathrm{Au} / \mathrm{TiO}_{2}$ catalyst were observed to have a pore volume $0.273 \mathrm{~cm}^{2} \mathrm{~g}^{-1}$, a pore radius $10.32 \mathrm{~nm}$, and a total surface area of $52.99 \mathrm{~m}^{2} \mathrm{~g}^{-1}$. Pore volume and surface area could be dependent on the strong interactions and support between $1 \mathrm{wt} \%$ $\mathrm{Au}$ and the $1 \mathrm{wt} \% \mathrm{Pd}$ and supported carbon [26]. For the $1 \mathrm{wt} \%(\mathrm{Au}-\mathrm{Pd}) / \mathrm{C}$ catalyst, the large surface area was ascribed to carbon support, whose surface area is known to be considerably larger compared to $\mathrm{TiO}_{2}$. The catalyst's surface area contributes to that catalyst's activity during a chemical reaction. Thus, it was found that $1 \mathrm{wt} \%(\mathrm{Au}-\mathrm{Pd}) / \mathrm{C}$ catalyst showed more activity compared to the $1 \mathrm{wt} \% \mathrm{Au} / \mathrm{TiO}_{2}$ catalyst.
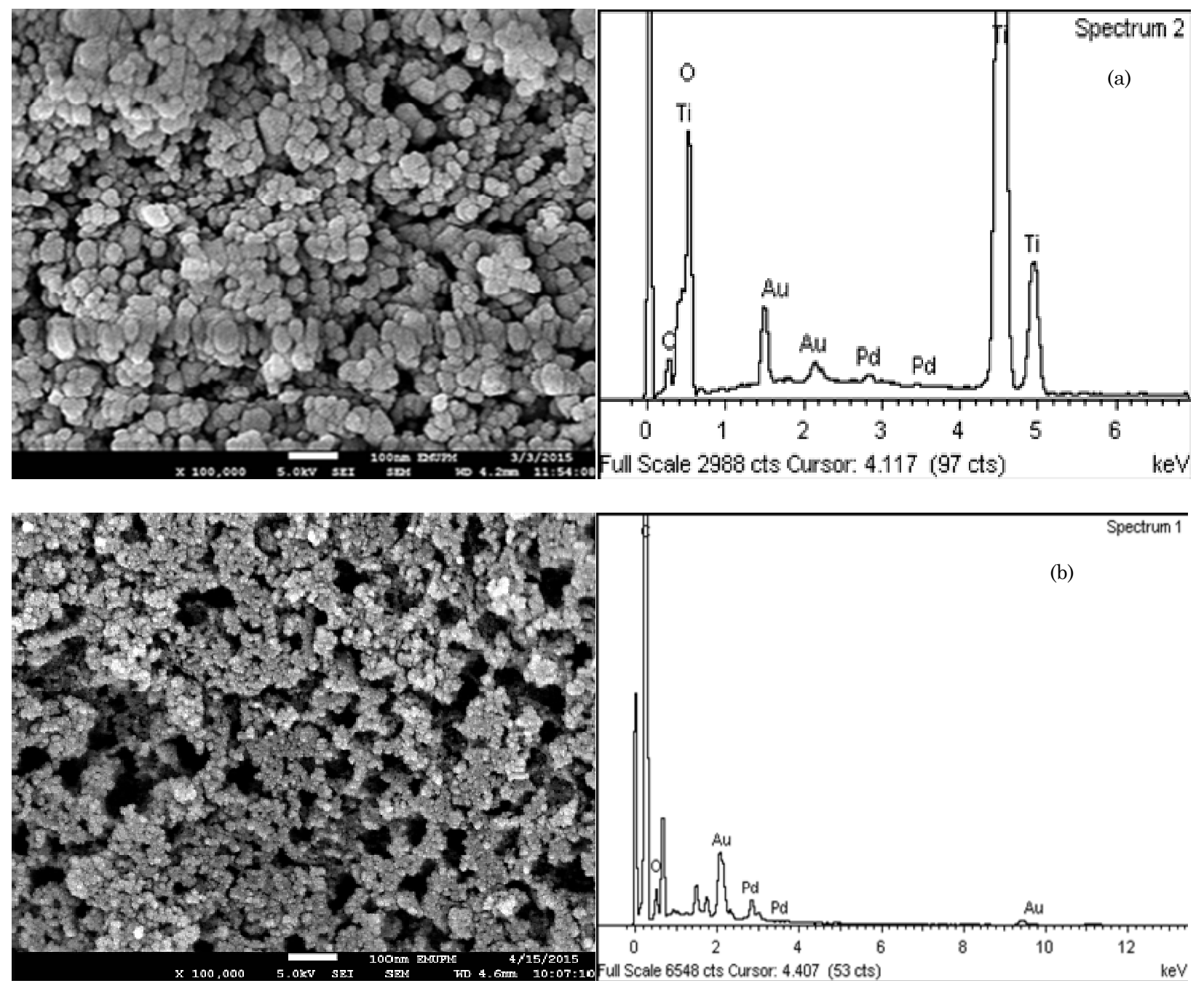

Figure 4. FESEM micrographs and EDX spectrum of (a) $1 \mathrm{wt} \%(\mathrm{Au}-\mathrm{Pd}) / \mathrm{TiO}_{2}$, and (b) $1 \mathrm{wt} \%(\mathrm{Au}-\mathrm{Pd}) / \mathrm{C}$ 


\subsection{Structure and crystallography}

Figure 5 shows the X-ray patterns for the catalyst samples of the synthesised $1 \mathrm{wt} \%$ (Au$\mathrm{Pd}) / \mathrm{C}$ and $1 \mathrm{wt} \%(\mathrm{Au}-\mathrm{Pd}) / \mathrm{TiO}_{2}$. An X-ray machine was used to achieve these patterns (Shimadzu model XRD 6000). The patterns obtained from the powdered materials were achieved utilizing $\mathrm{Cu}-\mathrm{Ka}$ emission. This was created using the Philips glass X-ray tube that was in extensive operation at $30 \mathrm{~mA}$ and $30 \mathrm{kV}$. For the dynamic carbon phase and palladium, the pattern took place at $2 \theta=26.4^{\circ}$ and $38.5^{\circ}$, correspondingly. Alloys of $\mathrm{Au} / \mathrm{Au}-\mathrm{Pd}$ were found to exist at $2 \theta=44.4^{\circ}, 64.39^{\circ}$, and $77^{\circ}$ (JCPDS card No. 00-001-1174). For 1 wt $\% \mathrm{Au}-\mathrm{Pd} / \mathrm{TiO}_{2}$, the diffraction peaks were observed at $2 \theta=$ $38.04^{\circ}$ and $49.15^{\circ}$ for $\mathrm{Au}$ and $\mathrm{Au}-\mathrm{Pd}$ samples and (JCPDS card No. 00-001-1172) for the $\mathrm{Au} / \mathrm{Au}-\mathrm{Pd}$ alloy, respectively. The diffraction peak was at $2 \theta=54.15^{\circ}$ for $\mathrm{TiO}_{2}$ and $2 \theta=77^{\circ}$ for $\mathrm{Pd}$. Because gold is cubic in nature, entirely the samples detected were exhibited cubic crystal shape system.

\subsection{Activity of $\mathrm{Au}-\mathrm{Pd} / \mathrm{C}$ and $\mathrm{Au}-\mathrm{Pd} / \mathrm{TiO}_{2}$ catalysts prepared by the sol immobilisation}

The utilisation of the Au-Pd catalyst for benzyl alcohol oxidation was examined using $\mathrm{H}_{2} \mathrm{O}_{2}$ as the oxidant. As shown in Figure 6, there is a clear rise in the benzyl alcohol transformation upon the addition of $\mathrm{Pd}$ to the $\mathrm{Au}$ catalyst supported on carbon. Sol immobilized catalyst showed the better activity in the reactions of benzyl alcohol oxidation, and that could be explained due to the intense synergy of particle size in addition to the inherent readiness of oxidation due to the nature of the distribution of the particles which is crucial [25].

Carbon demonstrated higher surface area in the structure of Au-Pd alloy, which is offering a superior metal dispersion compared to $\mathrm{TiO}_{2}$, where this feature could boost the tendency to form the comer/edges sites. As a principle, it is not sufficient for particle size or alloy structured type in separate to show the catalytic activity pattern, even though, the outstanding ac- tivity could be extracted from multi causes such as the surface composition of the bimetallic catalyst and the metal dispersion on support. Moreover, less amount of benzoic acid generated could be happening due to the restricted function of $\mathrm{TiO}_{2}$ in radical-related reaction.

$\mathrm{TiO}_{2}$ may capture hydroxyl $(\cdot \mathrm{OH})$, perhaps by absorbing them into the layer of its surface oxide [27]. In another word, the morphology and structure of the catalyst played a vital role
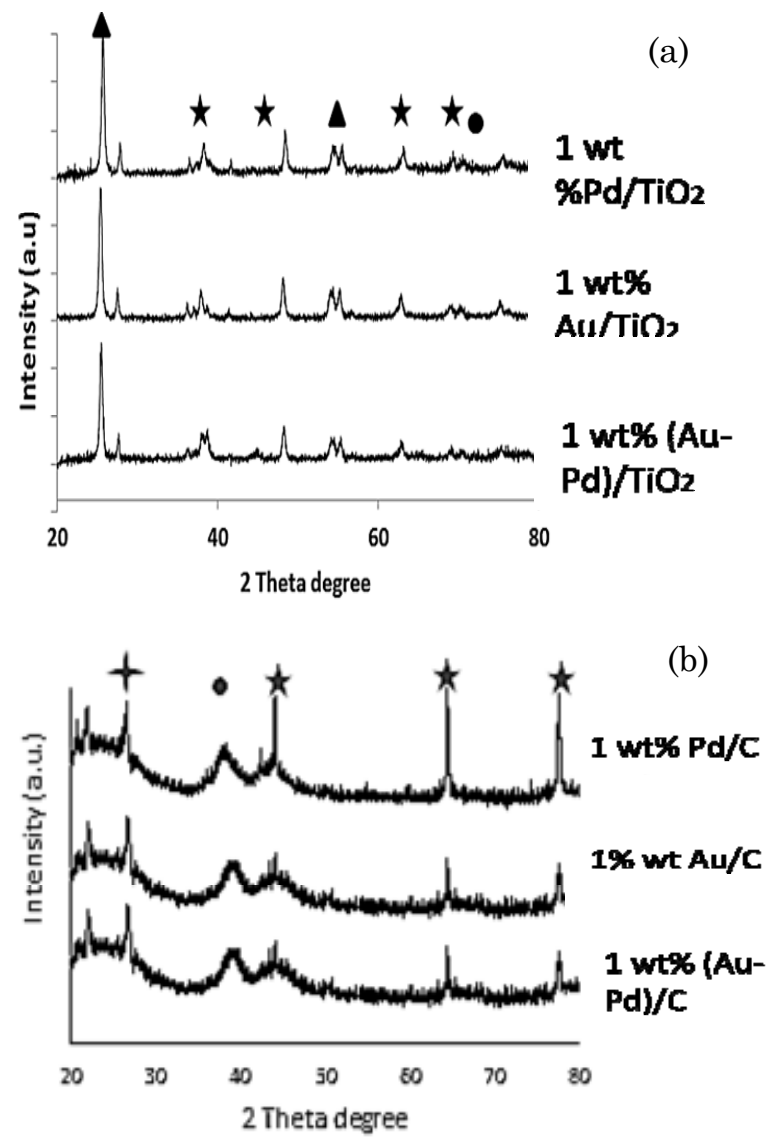

Figure 5. (a) X-ray diffiractogram for monometallic and bimetallic $\mathrm{Au}-\mathrm{Pd}$ using catalyst supported $\mathrm{TiO}_{2}$. Symbol Au/Au-Pd alloy *, $\mathrm{TiO}_{2}$ phase $\boldsymbol{\Lambda}$, and $\mathrm{Pd} \bullet$..., (b) X-ray diffractogram for monometallic and bimetallic Au-Pd by using catalyst supported carbon $\mathrm{Au}-\mathrm{Pd} / \mathrm{C}, \mathrm{Au}-\mathrm{Pd}$ alloy*, active carbon phase $f$, and $\operatorname{Pd} \bullet$.

Table 1. Specific surface area and average crystal size of the catalyst samples (a $=$ Brunauer-EmmetTeller (BET); $b$ = Debye-Scherrer equation of the XRD)

\begin{tabular}{ccccc}
\hline Sample Name & $\begin{array}{c}\text { BET Surface area } \\
\left(\mathrm{m}^{2} \mathrm{~g}^{-1}\right)\end{array}$ & $\begin{array}{c}\text { Pore volume } \\
\left(\mathrm{cm}^{3} \mathrm{~g}^{-1}\right)\end{array}$ & $\begin{array}{c}\text { Pore } \\
\text { Radius }(\mathrm{nm})\end{array}$ & $\begin{array}{c}\text { Crystallite size }^{\mathrm{b}} \\
(\mathrm{nm})\end{array}$ \\
\hline 1wt.\% Au-Pd/C & 870.9 & 0.8107 & 1.88 & 15.3 \\
$1 \mathrm{wt} \% \mathrm{Au}-\mathrm{Pd} / \mathrm{TiO}_{2}$ & 52.999 & 0.2735 & 10.321 & 26.68 \\
\hline
\end{tabular}


in the activity. The metal in the metal supported reaction affects the particles size and shape, where this with no a doubt would motivate different activities and would make all compounds that used to prepare the catalyst are productive. As a consequence, it is very important to control the shape and size of particles during the catalyst preparation (Figure 3 and 4). For sol immobilization preparation, adding $\mathrm{Pd}$ to $\mathrm{Au}$ supported on carbon led to the small particle distribution that caused rising the activity comparing to catalyst prepared using the impregnation procedure. As a result, this study demonstrated that Au-Pd catalyst supported carbon had TOF $\left(137.4 \mathrm{~h}^{-1}\right)$ that provided the highest performance after 4 hours of oxidation reaction.

The mono Au catalyst was not very active, in fact it showed poor activity for promoting disproportionation of toluene. Whilst, mono $\mathrm{Pd}$ catalyst has more effective nanoparticles for both processes. Though, more toluene formation higher than oxidation has occurred when extended period. The bimetallic Au-Pd catalyst revealed higher catalytic activity, it is recognized that this reactivity is a result of the small gold nanoparticles; their penetration with support texture is also paramount [28,29]. Moreover, it is found very useful to use the electron microscopy for extra details to explain the issue.

For this reaction, the major products synthesised were benzaldehyde followed by the formation of benzoic acid as a result of overoxidation [30]. In terms of the bimetallic Au$\mathrm{Pd} / \mathrm{TiO}_{2}$ catalyst, a decrease in the selectivity of benzaldehyde accompanied the conversion enhancement. This is a result of the distinct properties of every $\mathrm{Au} / \mathrm{TiO}_{2}$ and $\mathrm{Pd} / \mathrm{TiO}_{2}$ monometallic catalyst. One can then conclude that the alloyed $\mathrm{Au}-\mathrm{Pd} / \mathrm{TiO}_{2}$ bimetallic catalyst phase results into a higher combine effect that is observable from the XRD outcomes that are presented in Figure 5(a). Selectivity improvement took place in terms of the bimetallic goldpalladium alloy catalyst. For the bimetallic catalyst, maintaining its selectivity was almost less than that of the palladium or pure gold mono catalyst (Table 2).

With regards to the activity, higher activity was associated with the bimetallic Au-Pd catalyst compared to mono $\mathrm{Au}$ or Pd based on the TOF value. The results Table 2 of this study presented a comparison for the bimetallic $\mathrm{Au}-$ Pd catalyst for each case backed by carbon or titanium oxide. On evaluating different support, higher activity was seen with the bimetallic Au-Pd catalyst backed by carbon when com-

Table 2. Liquid phase oxidation of benzyl alcohol using $\mathrm{H}_{2} \mathrm{O}_{2}$ as an oxidant for mono and bimetallic $\mathrm{Au}-\mathrm{Pd}$ supported carbon and $\mathrm{TiO}_{2}$ catalysts prepared by sol-immobilisation. Reaction preformed for 4 hours. *Conditions of the reaction: Benzyl alcohol $=9.66 \mathrm{mmol}$; Catalyst: $0.15-0.30 \mathrm{~g}$; the ratio amount of the reactant $(\mathrm{mol}): \mathrm{H}_{2} \mathrm{O}_{2}(\mathrm{~mol})=10: 1$; SI: Sol-immobilisation, substrate/metal $=6674.03$; stirring rate $200-300 \mathrm{rpm} ; \mathrm{T}=80^{\circ} \mathrm{C}$; $\mathrm{TOF}^{\mathrm{b}}\left(\mathrm{h}^{-1}\right)$ at 4 hours. TOF numbers were computed based on the total loading of metal

\begin{tabular}{|c|c|c|c|c|c|c|}
\hline \multirow{2}{*}{ Catalyst } & \multirow{2}{*}{$\begin{array}{l}\text { Time } \\
\text { (h) }\end{array}$} & \multirow{2}{*}{$\begin{array}{c}\text { Conversion } \\
(\%)\end{array}$} & \multicolumn{3}{|c|}{ Selectivity (\%) } & \multirow{2}{*}{$\begin{array}{c}\mathrm{TOF} b \\
\left(\mathrm{~h}^{-1}\right)\end{array}$} \\
\hline & & & Toluene & Benzaldehyde & Benzoic Acid & \\
\hline \multirow{3}{*}{1 wt.\% $\mathrm{Au}-\mathrm{Pd} / \mathrm{TiO}_{2}(\mathrm{SI})$} & 0.5 & 3 & 7.8 & 89.6 & 2.5 & 398.4 \\
\hline & 2 & 4.5 & 6.9 & 86.9 & 6.2 & 151.2 \\
\hline & 4 & 8.2 & 6.4 & 83.9 & 9.7 & 137.4 \\
\hline \multirow{3}{*}{1 wt.\% $\mathrm{Pd} / \mathrm{TiO}_{2}(\mathrm{SI})$} & 0.5 & 1.1 & 4.7 & 89.3 & 5.9 & 152.0 \\
\hline & 2 & 1.2 & 2.9 & 88.9 & 8.2 & 40.8 \\
\hline & 4 & 1.7 & 2.9 & 88.2 & 8.9 & 28.4 \\
\hline \multirow{3}{*}{1 wt.\% $\mathrm{Au} / \mathrm{TiO}_{2}(\mathrm{SI})$} & 0.5 & 1.7 & 5.6 & 89.5 & $4 . .9$ & 230.6 \\
\hline & 2 & 2.2 & 5.3 & 88.4 & 6.3 & 71.9 \\
\hline & 4 & 2.5 & 3.8 & 86.8 & 9.4 & 41.0 \\
\hline \multirow{3}{*}{1 wt.\% Au-Pd/C (SI) } & 0.5 & 8.5 & 7.9 & 85.8 & 6.3 & 135.2 \\
\hline & 2 & 10.0 & 6.9 & 83.2 & 9.9 & 334.0 \\
\hline & 4 & 15.1 & 6.4 & 75.7 & 17.9 & 251.3 \\
\hline \multirow{3}{*}{1 wt.\% $\mathrm{Pd} / \mathrm{C}(\mathrm{SI})$} & 0.5 & 1.9 & 3.3 & 95.3 & 1.3 & 253.0 \\
\hline & 2 & 2.4 & 2.8 & 91.8 & 5.4 & 79.1 \\
\hline & 4 & 3.5 & 1.9 & 87.0 & 11.2 & 58.9 \\
\hline \multirow{3}{*}{1 wt.\% Au/C (SI) } & 0.5 & 2.4 & 6.5 & 90.1 & 3.4 & 316.3 \\
\hline & 2 & 3.3 & 6.3 & 89.1 & 4.6 & 108.9 \\
\hline & 4 & 5.5 & 4.9 & 88.8 & 6.3 & 91.4 \\
\hline
\end{tabular}


pared with the titanium, which could be because of the positive effect created by small nanoparticles size on the catalytic activity [31].

$\mathrm{Au}-\mathrm{Pd}$ catalyst backed by $\mathrm{TiO}_{2} 1$ wt.\% (Au$\mathrm{Pd} / \mathrm{TiO}_{2}$ was the most selective catalyst for benzaldehyde formation, which also showed higher selectivity (83.9\%) but with a little lower transformation than with carbon supported catalyst. The high activity in sol immobilized catalyst in benzyl alcohol oxidation reaction was observed to be linked substantially to Au$\mathrm{Pd}$ particle size effect, particularly their distribution which has had more importance than the effect of oxidation state [32].

The obtained results also revealed that an increase in selectivity was shown by both bimetallic catalysts towards benzoic acid production. Therefore, it was clear that the selectivity increase was greater with $1 \mathrm{wt} \%(\mathrm{Au}-\mathrm{Pd}) / \mathrm{C}$, which indicates that benzoic acid is produced due to over-oxidation of benzaldehyde during the reaction. These results demonstrate how important it is to select the correct support for the metal nanoparticles catalyst. Some dissimilarities could be seen in the selectivity and catalytic actions between the catalysts, which could be due to the interaction of catalyst support as well as the influence of the shape of metal particles.
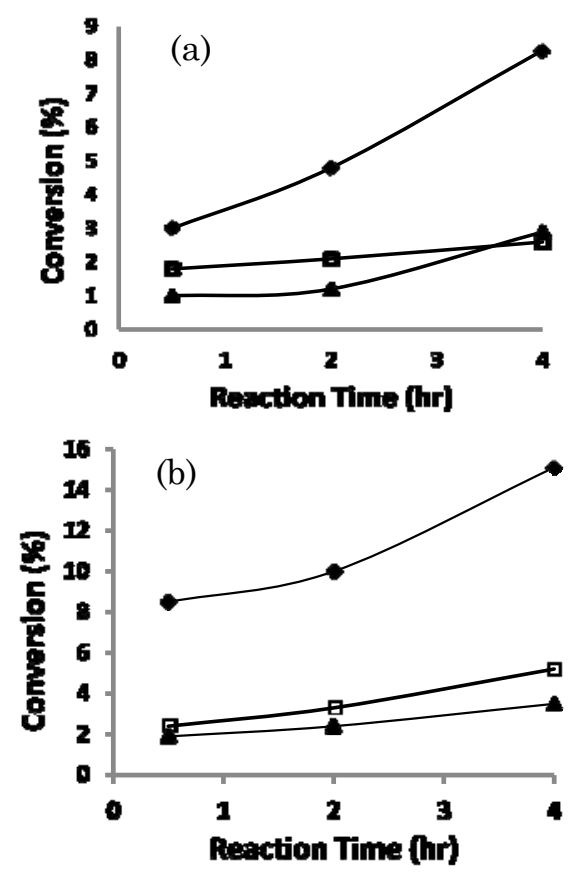

Figure 6. Benzyl alcohol oxidation reaction for monometallic and bimetallic Au-Pd supported $\mathrm{TiO}_{2}$ and carbon catalysts synthesised via solimmobilisation method

\subsection{Effect of reaction time}

A perfect desired reaction can be guaranteed with optimum duration for the reaction to occur. The impact of time with the Au-Pd catalyst support titanium and carbon on the benzyl alcohol reaction catalyst oxidation is presented in Figure 7 as follows: various time intervals were considered to study the reaction as well as to analyse the impact of time duration on the oxidation reaction of benzyl alcohol. With passing time, a gradual increase in the conversion was seen. We recorded the reduction in selectivity towards benzaldehyde, which was because of the consecutive oxidation occurring for the desired product, i.e. benzaldehyde. A peak conversion of $30.7 \%$ is reached after 8 hours along with $81.4 \%$ benzaldehyde selectivity. However, an optimal duration of 6-hour reaction time was chosen to achieve a significant conversion of $28.5 \%$ for benzyl alcohol and $84.9 \%$ selectivity to benzaldehyde simultaneously.

\subsection{Impact of heat treatment process}

To improve catalyst performance, heat treatment or thermal activation is considered a crucial process. Clear effects on the metal were observed due to the heat treatment, with regards to morphology of particle surface, particle size distribution and metal distribution on the support $[33,26]$. Three different thermal activation procedures were employed for the 1 wt\% (Au-Pd)/ $/ \mathrm{TiO}_{2}$ catalysts sample: (i) a tem-

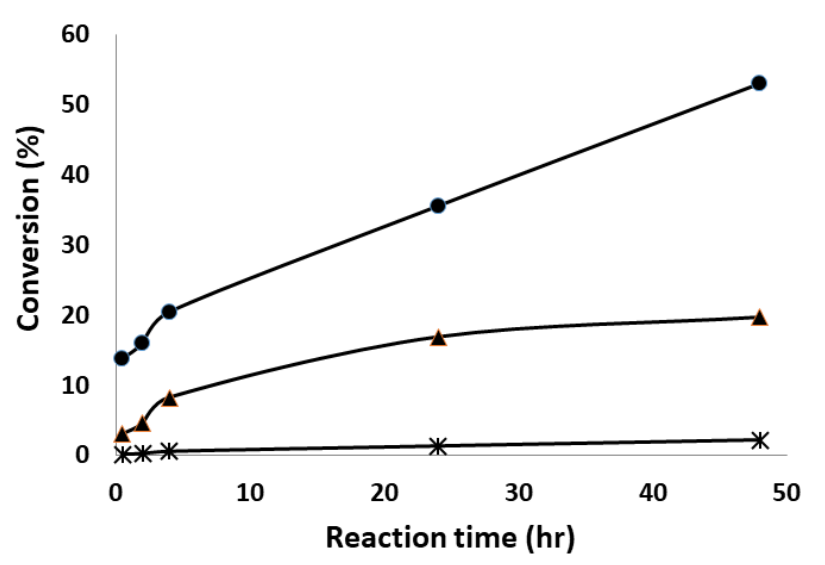

Figure 7. Time on-line plot for benzyl alcohol oxidation in the term of conversion. Reaction conditions: benzyl alcohol $10 \mathrm{~mL}, \mathrm{~T}=80^{\circ} \mathrm{C}$, ratio benzyl alcohol (mol): $\mathrm{H}_{2} \mathrm{O}_{2}(\mathrm{~mol})=10: 1$. Key: * conversion of benzyl alcohol without catalyst (\%); $\boldsymbol{\Delta}$ conversion of benzyl alcohol with $1 \mathrm{wt} . \%$ $\mathrm{Au}-\mathrm{Pd} / \mathrm{TiO}_{2 \mathrm{SI}}(\%)$; $\bullet$ conversion of benzyl alcohol with $1 \mathrm{wt} \% \mathrm{AuPd} / \mathrm{C}_{\text {SI }}(\%)$ 
perature of $250{ }^{\circ} \mathrm{C}$ was set to thermally activate the dried $1 \mathrm{wt} \%(\mathrm{Au}-\mathrm{Pd}) / \mathrm{TiO}_{2}$ along with nitrogen flow of 3 hours, at a rate of heating of 5 ${ }^{\circ} \mathrm{C} / \mathrm{min}$; (ii) a temperature of $250^{\circ} \mathrm{C}$ was set to thermally activate the dried $1 \mathrm{wt} \% \mathrm{Au}-\mathrm{Pd} / \mathrm{TiO}_{2}$ under hydrogen flow for 3 hours, at a heating rate of $5{ }^{\circ} \mathrm{C} / \mathrm{min}$; (iii) a temperature of $250{ }^{\circ} \mathrm{C}$ was set to thermally activate the dried $1 \mathrm{wt} \%$ (Au-Pd) $/ \mathrm{TiO}_{2}$ in exposed air flow for 3 hours, under the heating rate of $5{ }^{\circ} \mathrm{C} / \mathrm{min}$. Under flow air conditioning at a temperature of $250{ }^{\circ} \mathrm{C}$, the impact of thermal activation was assessed for the 1 wt\% (Au-Pd)/ $\mathrm{TiO}_{2}$ sample as demonstrated in Figure 7. A substantial rise in the particle dimension from lesser $(3.5-3.9 \mathrm{~nm})$ to bigger (8-10 nm) was observed, while the distribution of particle size became more prevalent as presented in Figure 3.

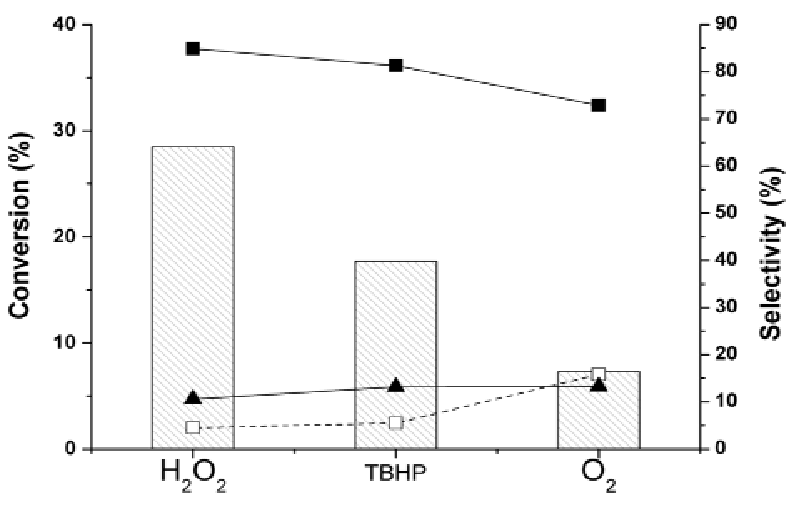

Figure 8. Impact of different oxidants on the conversion and selectivity of $1 \mathrm{wt} \%(\mathrm{Au}-\mathrm{Pd}) / \mathrm{C}_{\mathrm{SI}}$ catalyst for the selective benzyl alcohol oxidation reaction, Key: • conversion (\%); Selectivity of: - benzaldehyde (\%); $\boldsymbol{\Delta}$ benzoic acid (\%); $\square$ toluene $(\%) ; \mathrm{T}=80{ }^{\circ} \mathrm{C}$
In this study, the sol-immobilisation technique with protecting agent of (PVA) and $\mathrm{NaBH}_{4}$ as reducing agent to Au-Pd precursor was employed to produce the catalyst $\mathrm{Au}-\mathrm{Pd}$ supported on titanium oxide and carbon. To the synthesised catalysts, thermal activation was applied to remove a major chunk of the protective agent (PVA) from the metal surface, subsequently leading to a momentous improvement for access to the gold-palladium's surface area. Furthermore, the thermal activation would also have an impact on the distribution of the metal particle size. Table 3 lists out the obtained results from different thermal procedures. An increase in conversion resulted in a decline in benzaldehyde selectivity. While, on further increasing, selectivity could be observed towards benzoic acid. After the reaction develops, the highest value was achieved with the selectivity to toluene, and on further increasing the conversion, the selectivity started decreasing. Table 3 clearly lists out the thermal activation with regards to the performance and use in all cases. A significant impact of the gas flow nature employed in the thermal activation was seen on the products distribution with the synthesised materials employed as catalysts to allow oxidation of benzyl alcohol. Utilising airstream gave the best performance (indicated by TOF), followed by hydrogen gas and then nitrogen gas. The contact amongst the metal could increase the activity. Variations in the catalyst's physico-chemical properties could be induced due to the impact of thermal activation. These include morphology, particle size, metal dispersion on the support, generation of the active site, degree of alloying, stability and catalytic performance [33]. Change in the number of gold sites producing

Table 3. Liquid phase oxidation of benzyl alcohol for samples containing $1 \mathrm{wt} \%(\mathrm{Au}-\mathrm{Pd}) / \mathrm{TiO}_{2}$ of metal synthesized by the sol-immobilisation method. Reaction performed for 4 hours. aReaction conditions: benzyl alcohol $=9.66 \mathrm{mmol}$; catalyst $0.2 \mathrm{~g}$; ratio amount of the reactant $(\mathrm{mol}): \mathrm{H}_{2} \mathrm{O}_{2}(\mathrm{~mol})=10: 1$; SI: solimmobilisation; substrate $/$ metal $=6674.03$; stirring rate $200-300 \mathrm{rpm} ; \mathrm{T}=80{ }^{\circ} \mathrm{C} ; \mathrm{TOF}^{\mathrm{b}}\left(\mathrm{h}^{-1}\right)$ at 4 hours reaction time

\begin{tabular}{|c|c|c|c|c|c|c|}
\hline \multirow{2}{*}{ Catalyst } & \multirow{2}{*}{$\begin{array}{l}\text { Time } \\
\text { (h) }\end{array}$} & \multirow{2}{*}{$\begin{array}{c}\text { Conversion } \\
(\%)\end{array}$} & \multicolumn{3}{|c|}{ Selectivity (\%) } & \multirow{2}{*}{$\begin{array}{l}\mathrm{TOF}^{\mathrm{b}} \\
\left(\mathrm{h}^{-1}\right)\end{array}$} \\
\hline & & & Toluene & Benzaldehyde & Benzoic Acid & \\
\hline \multirow{3}{*}{$\begin{array}{c}1 \text { wt.\% }(\mathrm{Au}-\mathrm{Pd}) / \mathrm{TiO}_{2} \\
\text { (SI) } \mathrm{H}_{2} / \text { Argon }\end{array}$} & 0.5 & 5.2 & 2.8 & 94.6 & 2.6 & 687.4 \\
\hline & 2 & 7.5 & 2.3 & 91.4 & 6.2 & 250.3 \\
\hline & 4 & 12.1 & 1.7 & 86.2 & 12.1 & 202.4 \\
\hline \multirow{3}{*}{$\begin{array}{c}1 \text { wt. } \%(\mathrm{Au}-\mathrm{Pd}) / \mathrm{TiO}_{2} \\
\text { (SI) } \mathrm{N}_{2}\end{array}$} & 0.5 & 4.2 & 2.4 & 95.1 & 2.4 & 560.9 \\
\hline & 2 & 5.8 & 1.9 & 90.5 & 7.6 & 193.6 \\
\hline & 4 & 11.1 & 0.6 & 88.5 & 11.0 & 185.0 \\
\hline \multirow{3}{*}{$\begin{array}{c}1 \text { wt.\% (Au-Pd)/TiO } \\
\text { (SI) Air }\end{array}$} & 0.5 & 5.9 & 14.6 & 80.3 & 5.1 & 789.4 \\
\hline & 2 & 7.2 & 12.0 & 77.5 & 10.5 & 239.6 \\
\hline & 4 & 14.8 & 10.1 & 76.5 & 13.4 & 246.2 \\
\hline
\end{tabular}


toluene could result in the increase of thermal treatment procedure, which could be attributed to the removal of the remaining polymer that was earlier blocking the active sites of gold [34]. Furthermore, the hydrogen presence on the gold surface was confirmed with the realization of toluene as a result of hydrogenolysis of $\mathrm{C}-\mathrm{O}$ bonds in benzyl alcohol. Besides, the available gold superficial area was enhanced due to heat treatment or thermal activation, which, during the reaction, could result in a rise in the quantity of $\mathrm{Au}-\mathrm{H}$ species [35].

\subsection{Possible reaction mechanism}

In Figure 10, a comment is warranted by the chemistry involved in the formation of benzaldehyde. In this new science, selectivity and mechanism are prominent features that must be well understood to help in fine tuning and designing the catalyst. It is thus crucial to understand all reactions that could be parallel or consecutive, which remain active in the overall transformation. This sometimes can result in side-products and also a lower selectivity towards the product of interest [12,13,36-38].

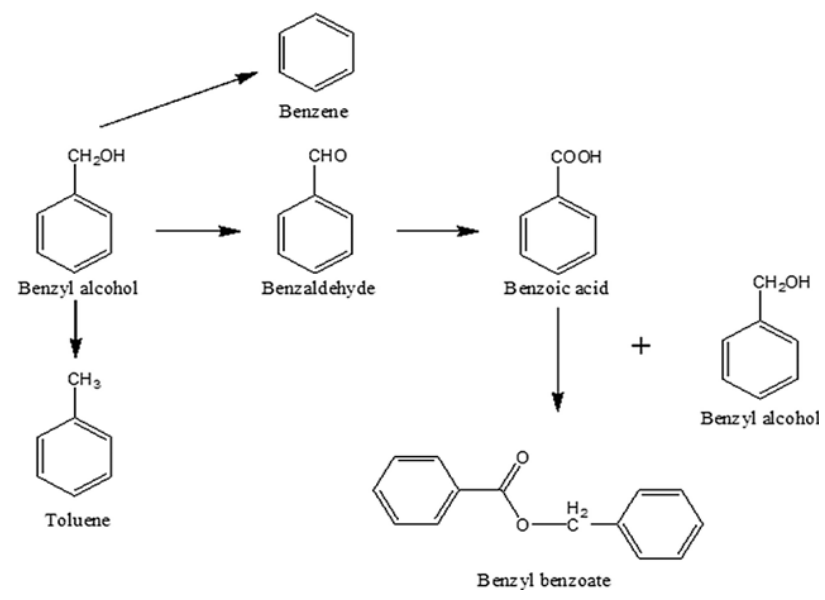

Figure 10. Possible reaction mechanism of benzyl alcohol oxidation

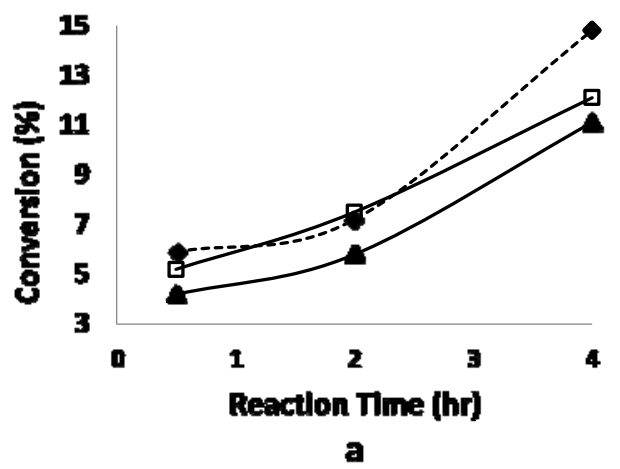

Various reactions are involved in the reaction with benzyl alcohol, which depends on the conditions of the reaction and the type of catalyst employed. So far, oxidation reactions have been reported to form benzoic acid, benzaldehyde and benzyl benzoate [31]. Firstly, direction oxidation of benzyl alchohol to bezaldehahyde, benzoic acid and benzyl benzoate [31]. The essential demanded process is the selective oxidation of benzyl alcohol to benzaldehyde, and the essential side reaction is the selfdisproportionation to synthesize benzaldehyde and toluene under the given conditions used by Hutiching and co-workers [39]. Secondly, pair of benzyl alcohol molecules witnessed selfdisproportionation to synthesis benzaldehyde, toluene and water, toluene and benzaldehyde were noticed in almost equal amounts, where toluene has had a chance to be formed when the reaction was conducted in equivalent circumstances [40].

Further, in case of catalyst showed activity towards dehydrogenation, then an increasing in toluene formation has occurred due to the growth in hydrogen surface, where the reaction produced toluene as another main product [40]. Thirdly, dehydration for dibenzylether formation [41]. Fourthly, forming anthracene and stilbene due to benzylation (self-condensation) [42].

\subsection{Comments on the mechanism}

Our observation confirmed by previous literatures that, benzyl alcohol has the ability of transforming under non-oxidative conditions into mixture of equimolar benzaldehyde, and toluene points to a disproportionation mechanism in which both products are formed by a transition state obtained from the participation of the catalyst surface by a pair of molecules of the alcohol $[40,43]$. The microscopy results of Au-Pd catalyst particles using various supports have not remarked a clear differences

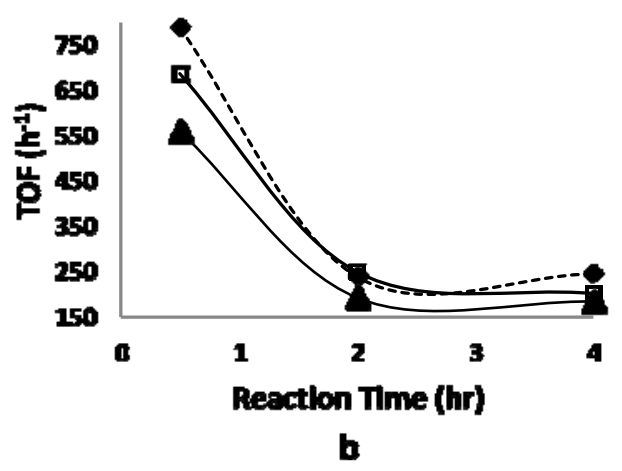

Figure 9. Conversion versus reaction time (a); TOF versus reaction time (b) 
in their physical appearance, this may clarify the disparity in the activity of catalysis of disproportion; that indicates more chemical interpretation.

At the start of oxidation reaction, toluene was one amongst the product compounds employing $1 \% \mathrm{Au}-\mathrm{Pd}$ catalyst supported by $\mathrm{TiO}_{2}$, which was prepared via sol immobilisation. Toluene can be formed despite the existence of $\mathrm{TiO}_{2}$ as catalyst support, which suggests the decisive factors involved in controlling the catalysis at disproportionation reaction, i.e. the acidity/basicity or the catalytic surface. The $\mathrm{C}-\mathrm{O}$ bonds in benzyl alcohol need to be cleaved to produce toluene. When compared with the carbocation chemistry, this could probably promote acidic environments and inhibition under basic conditions, in which the preferred $\mathrm{O}-\mathrm{H}$ cleavage is predicted.

If acidic substances are associated with the $\mathrm{Au}-\mathrm{Pd}$ catalyst particles, toluene is preferred via disproportionation. However, this will never occur if the employed initial supports fit into this simple view. In such a condition, catalytic relevant sites can be identified near the metal particles' periphery, where metal and support surfaces are completely in close contact [40].

\section{Conclusions}

Gold palladium monometallic and bimetallic catalysts were effectually synthesised by deploying the sol-immobilisation technique. The catalytic performance of synthesising catalysts was put to test for determining the impact of $\mathrm{H}_{2} \mathrm{O}_{2}$ as an oxidant for benzyl alcohol's solventfree liquid phase oxidation. The solimmobilisation catalyst synthesis approach led to Au-Pd catalyst supported on carbon and titanium oxide with nano crystalline materials and show higher activity.

Quite narrow metal particle dimension disseminations, which exhibited remarkable catalytic activity that was much more improved compared to those earlier synthesised using other approaches like the impregnation technique. Catalyst support is a key consideration during preparation of the catalyst, considering it impacts the surface area as well as particle size distribution of palladium and gold catalysts. This study used two catalyst support $\left(\mathrm{TiO}_{2}\right.$ and $\left.\mathrm{C}\right)$. Carbon supported Au-Pd demonstrates improved catalytic activity with regard to solvent-free oxidation, because of the huge superficial area of carbon supported catalyst in comparison to titanium supported catalyst. Furthermore, heat handling of the synthesised catalysts significantly impacts the particle dimension distribution as well as catalytic activity.

\section{Acknowledgements}

The authors would like to express their gratitude to the University of Baghdad, Iraq, for the $\mathrm{PhD}$ sponsorship to one of authors (Sanaa T. Sarhan. Al-saedi). The authors would also like to thank the Universiti Putra Malaysia for offering the grant for conducting this study.

\section{References}

[1] Enache, D.I., Knight, D.W., Hutchings, G.J. (2005). Solvent-Free Oxidation of Primary Alcohols to Aldehydes Using Supported Gold Catalysts. Catalysis Letters, 103(1-2): 43-52.

[2] Vazylyev, M., Sloboda-Rozner, D., Haimov, A., Maayan, G., Neumann, R. (2005). Strategies for Oxidation Catalyzed by Polyoxometalates at the Interface of Homogeneous and Heterogeneous Catalysis. Topics in catalysis, 34(1-4): 93-99.

[3] Mori, K., Hara, T., Mizugaki, T., Ebitani, K., Kaneda, K. (2004). HydroxyapatiteSupported Palladium Nanoclusters: A Highly Active Heterogeneous Catalyst for Selective Oxidation of Alcohols by Use of Molecular Oxygen. Journal of the American Chemical Society, 126(34): 10657-10666.

[4] Pagliaro, M., Campestrini, S., Ciriminna, R. (2005). Ru-Based Oxidation Catalysis. Chemical Society Reviews, 34(10): 837-845.

[5] Sheldon, R.A., Arends, I.W.C.E., Dijksman, A. (2000). New developments in Catalytic Alcohol Oxidations for Fine Chemicals Synthesis. Catalysis Today, 57(1): 157-166..

[6] Lee, D.G., Spitzer, U.A. (1970). Aqueous Dichromate Oxidation of Primary Alcohols. The Journal of Organic Chemistry, 35(10): 35893590 .

[7] Griffith, W.P., Jolliffe, J.M. (1991). Ruthenium and osmium carboxylato oxo complexes as organic oxidants. Studies in Surface Science and Catalysis, 66: 395-400.

[8] Cainelli, G., Cardillo, G. (2012). Chromium oxidations in organic chemistry (Vol. 19). Springer Science \& Business Media.

[9] Schank, J. (1983). Catalytic gold: Applications of Clemental Gold in Heterogeneous Catalysis. Gold Bull. 16: 103.

[10] Bond, G.C., Thompson, D.T. (1999). Catalysis by Gold. Catalysis Reviews, 41(3-4): 319-388. 
[11] Haruta, M. (2003). When Gold Is Not Noble: Catalysis by Nanoparticles. The Chemical Record, 3(2): 75-87.

[12] Enache, D.I., Barker, D., Edwards, J.K., Taylor, S.H., Knight, D.W., Carley, A.F., Hutchings, G.J. (2007). Solvent-Free Oxidation of Benzyl Alcohol Using TitaniaSupported Gold-Palladium Catalysts: Effect of $\mathrm{Au}-\mathrm{Pd}$ Ratio on Catalytic Performance. $\mathrm{Ca}$ talysis Today, 122(3): 407-411.

[13] Sheldon, R.A., Arends, I.W., ten Brink, G.J., Dijksman, A. (2002). Green, Catalytic Oxidations of Alcohols. Accounts of Chemical Research, 35(9): 774-781.

[14] Hutchings, G.J. (2008). Nanocrystalline Gold and Gold Palladium Alloy Catalysts for Chemical Synthesis. Chemical Communications, (10): 1148-1164.

[15] Enache, D.I., Edwards, J.K., Landon, P., Solsona-Espriu, B., Carley, A.F., Herzing, A.A., Watanabe, M., Kiely, C.J., Knight, D.W., Hutchings, G.J. (2006). Solvent-Free Oxidation of Primary Alcohols to Aldehydes Using $\mathrm{Au}-\mathrm{Pd} / \mathrm{TiO}_{2}$ Catalysts. Science, 311(5759):362365.

[16] Hashmi, A.S.K., Hutchings, G.J. (2006). Gold catalysis. Angewandte Chemie International Edition, 45(47): 7896-7936.

[17] Solsona, B.E., Edwards, J.K., Landon, P., Carley, A.F., Herzing, A., Kiely, C.J., Hutchings, G.J. (2006). Direct Synthesis of Hydrogen Peroxide from $\mathrm{H}_{2}$ and $\mathrm{O}_{2}$ Using $\mathrm{Al}_{2} \mathrm{O}_{3}$ Supported Au-Pd Catalysts. Chemistry of Materials, 18(11): 2689-2695.

[18] Chen, M., Kumar, D., Yi, C.W., Goodman, D.W. (2005). The promotional Effect of Gold in Catalysis by Palladium-Gold. Science, 310(5746): 291-293.

[19] Bianchi, C.L., Canton, P., Dimitratos, N., Porta, F., Prati, L. (2005). Selective Oxidation of Glycerol With Oxygen Using Mono and Bimetallic Catalysts Based on $\mathrm{Au}, \mathrm{Pd}$, and $\mathrm{Pt}$ Metals. Catalysis Today, 102: 203-212.

[20] Pawelec, B., Venezia, A.M., La Parola, V., Cano-Serrano, E., Campos-Martin, J.M., Fierro, J.L.G. (2005). AuPd Alloy Formation in $\mathrm{Au}-\mathrm{Pd} / \mathrm{Al}_{2} \mathrm{O}_{3}$ Catalysts and Its Role on Aromatics Hydrogenation. Applied Surface Science, 242(3): 380-391.

[21] Dimitratos, N., Lopez-Sanchez, J.A., Morgan, D., Carley, A., Prati, L., Hutchings, G.J. (2007). Solvent Free liquid Phase Oxidation of Benzyl Alcohol Using Au Supported Catalysts Prepared Using a Sol Immobilization Technique. Catalysis Today, 122(3): 317-324.

[22] bin Saiman, M.I., Brett, G.L., Tiruvalam, R., Forde, M.M., Sharples, K., Thetford, A., Jenkins, R.L., Dimitratos, N., Lopez-Sanchez,
J.A., Murphy, D.M., Bethell, D. (2012). Involvement of Surface-Bound Radicals in the Oxidation of Toluene Using Supported Au-Pd Nanoparticles. Angewandte Chemie International Edition, 51(24): 5981-5985.

[23] Link, S., El-Sayed, M.A. (1999). Size and Temperature Dependence of the Plasmon Absorption of Colloidal Gold Nanoparticles. The Journal of Physical Chemistry B, 103(21): 4212-4217.

[24] Dimitratos, N., Lopez-Sanchez, J.A., Lennon, D., Porta, F., Prati, L., Villa, A. (2006). Effect of Particle Size on Monometallic and Bimetallic $(\mathrm{Au}, \mathrm{Pd}) / \mathrm{C}$ on the Liquid Phase Oxidation of Glycerol. Catalysis Letters, 108(3-4): 147153.

[25] Dimitratos, N., Lopez-Sanchez, J.A., Anthonykutty, J.M., Brett, G., Carley, A.F., Tiruvalam, R.C., Herzing, A.A., Kiely, C.J., Knight, D.W., Hutchings, G.J. (2009). Oxidation of Glycerol Using Gold-Palladium AlloySupported Nanocrystals. Physical Chemistry Chemical Physics, 11(25): 4952-4961.

[26] Bailón-García, E., Carrasco-Marín, F., PérezCadenas, A.F., Maldonado-Hódar, F.J. (2015). Development of Carbon Xerogels as Alternative Pt-Supports for the Selective Hydrogenation of Citral. Catalysis Communications, 58: 64-69.

[27] Ab Rahim, M.H. (2011). Heterogeneous Gold, Palladium and Copper Based Catalysts for Liquid Phase Oxidation of Methane. Cardiff University (United Kingdom).

[28] Lopez, N., Nørskov, J.K. (2002). Theoretical Study of the $\mathrm{Au} / \mathrm{TiO}_{2}$ (110) Interface. Surface Science, 515(1): 175-186.

[29] Casaletto, M.P., Longo, A., Venezia, A.M., Martorana, A., Prestianni, A. (2006). MetalSupport and Preparation Influence on the Structural and Electronic Properties of Gold Catalysts. Applied Catalysis A: General, 302(2): 309-316.

[30] Fang, Y.L., Miller, J.T., Guo, N., Heck, K.N., Alvarez, P.J., Wong, M.S. (2011). Structural Analysis of Palladium-Decorated Gold Nanoparticles as Colloidal Bimetallic Catalysts. Catalysis Today, 160(1): 96-102.

[31] Dimitratos, N., Lopez-Sanchez, J.A., Morgan, D., Carley, A.F., Tiruvalam, R., Kiely, C.J., Bethell, D., Hutchings, G.J. (2009). SolventFree oxidation of Benzyl Alcohol Using AuPd Catalysts Prepared by Sol Immobilisation. Physical Chemistry Chemical Physics, 11(25): 5142-5153.

[32] Miedziak, P., Sankar, M., Dimitratos, N., Lopez-Sanchez, J.A., Carley, A.F., Knight, D.W., Taylor, S.H., Kiely, C.J., Hutchings, G.J. (2011). Oxidation of Benzyl Alcohol Using 
Supported Gold-Palladium Nanoparticles. Catalysis Today, 164(1): 315-319.

[33] Shi, Y., Yang, H., Zhao, X., Cao, T., Chen, J., Zhu, W., Yu, Y., Hou, Z. (2012). Au-Pd Nanoparticles on Layered Double Hydroxide: Highly Active Catalyst for Aerobic Oxidation of Alcohols in Aqueous Phase. Catalysis Communications, 18: 142-146.

[34] Behera, G.C., Parida, K.M. (2012). Liquid Phase Catalytic Oxidation of Benzyl Alcohol to Benzaldehyde Over Vanadium Phosphate Catalyst. Applied Catalysis A: General, 413: 245-253.

[35] Villa, A., Janjic, N., Spontoni, P., Wang, D., Su, D.S., Prati, L. (2009). Au-Pd/AC as Catalysts for Alcohol Oxidation: Effect of Reaction Parameters on Catalytic Activity and Selectivity. Applied Catalysis A: General, 364(1): 221-228.

[36] Matsumoto, T., Ueno, M., Wang, N., Kobayashi, S. (2008). Recent Advances in Immobilized Metal Catalysts for Environmentally Benign Oxidation of Alcohols. Chemistry-An Asian Journal, 3(2): 196-214.

[37] Shi, F., Tse, M.K., Beller, M. (2007). A Novel Environmentally Benign Method for the Selective Oxidation of Alcohols to Aldehydes and Ketones. Chemistry-An Asian Journal, 2(3): 411-415.
[38] Mallat, T., Baiker, A. (2004). Oxidation of Alcohols with Molecular Oxygen on Solid Catalysts. Chemical Reviews, 104(6): 3037-3058.

[39] Hutchings, G.J. (2014). Selective Oxidation Using Supported Gold Bimetallic and Trimetallic Nanoparticles. Catalysis Today, 238:, 6973 .

[40] Meenakshisundaram, S., Nowicka, E., Miedziak, P.J., Brett, G.L., Jenkins, R.L., Dimitratos, N., Taylor, S.H., Knight, D.W., Bethell, D., Hutchings, G.J. (2010). Oxidation of Alcohols Using Supported Gold and GoldPalladium Nanoparticles. Faraday Discussions, 145: 341-356.

[41] Jayamani, M., Pillai, C.N. (1983). Hydride Transfer Reactions: VIII. Reactions of Benzyl Alcohol Over Alumina: Dehydration and Disproportionation. Journal of Catalysis, 82(2): 485-488.

[42] Valarivan, R., Pillai, C.N., Swamy, C.S. (1996). Reaction of Benzyl Alcohol Over the Hydrogen Storage Intermetallic Compound $\mathrm{Mg}_{2} \mathrm{Cu}$. Reaction Kinetics and Catalysis Letters, 59(2): 343-350..

[43] Kovtun, G., Kameneva, T., Hladyi, S., Starchevsky, M., Pazdersky, Y., Stolarov, I., Vargaftik, M., Moiseev, I. (2002). Oxidation, Redox Disproportionation and Chain Termination Reactions Catalysed by the Pd-561 Giant Cluster. Advanced Synthesis and Catalysis, 344(9): 957-964. 